\title{
DECISION-MAKING STRATEGIES REGARDING LOGISTICS ORGANIZATION
}

\author{
Ioana Olariu \\ "Vasile Alecsandri” University of Bacau \\ ioana_barin_olariu@yahoo.com
}

\begin{abstract}
In the face of higher costs of operation and increasing pressures from customers for better service, the logistics organization must adapt to meet the challenge. An understanding of the factors that make organizations effective, and a knowledge of how these factors interrelate, are the first steps towards developing the system for a firm's customers. Logistics organizations must of necessity become more cost and service efficient. An understanding of the factors that affect a firm's organizational effectiveness, along with strategies to reveal weaknesses or deficiencies, can help create more efficient logistics systems. Organizational changes form the basis for procedural modifications that can reduce costs or improve service. Many firms have shown significant improvements in their logistics cost-service mix as a result of organizational changes. Logistics organizations are generally structured along the following lines: strategic versus operational, centralized versus decentralized and line versus staff, in various combinations. There is no single ideal organizational structure, but there are important elements that comprise an effective organization. In general, the factors contributing to organizational effectiveness can be categorized as organizational characteristics, environmental characteristics, employee characteristics, and managerial policies and practices.
\end{abstract}

Keywords

decision; effectiveness; logistics; organization; strategy

JEL Classification

M31

\section{Introduction}

An organization can and should establish a mission statement to define its overall purpose for existence. On an organizational level, mission statements provide a foundation upon which a company develops strategies, plans and tactics. It defines the basic purpose of an organization and identifies the parameters under which the firm will operate (Fuller, O’Connor and Rawlinson, 1993). Forms need a clear statement of purpose in order to develop the best combination of activities that must be performed in day-to-day operations of the enterprise. In sum, the logistics mission statement is an important document to guide the planning, implementation, and control of a firm's logistics activities (Grant et al., 2006).

\section{Components of an optimal logistics organization}

Many factors can influence the effectiveness of a logistics organization. In general, the factors contributing to organizational effectiveness can be summarized as: organizational characteristics; environment characteristics; employee characteristics and managerial policies and practices (Grant et al., 2006). 


\section{Organizational and environmental characteristics}

Structure and technology are the major components of a firm's organizational characteristics. Structure refers to the relationships that exist between various functional areas: interfunctional (marketing, finance, operations, manufacturing, logistics) or intrafunctional (warehousing, traffic, purchasing, customer service). The relationships are frequently represented by a company's organization chart. Examples of structural variables are decentralization, specialization, formalization, span of control, organization size and work-unit size. Technology refers to the mechanisms used by an organization to transform raw inputs into finished outputs. Technology can take several forms, including variations in the materials used, and variations in the technical knowledge brought to bear on goal-directed activities. The effectiveness of the organization is influenced by factors internal and external to the firm. Internal factors, which are more or less controllable by the logistics executive, are known as organizational climate. Sometimes, this is referred to as corporate culture. External factors, sometimes referred to as uncontrollable elements, include the political and legal, economic, cultural and social, and competitive environments.

\section{Employee characteristics}

The keys to effective organizations are the employees who "tick the boxes" on the organization chart. The ability of individuals to carry out their respective job responsibilities ultimately determines the overall effectiveness of any organization. All employees possess different outlooks, goals, needs and abilities. These human variations often cause people to behave differently, even when placed in the same work environment. Moreover, individual differences can have a direct bearing on two important organizational processes that can have a marked impact on effectiveness. These are organizational attachment, or the extent to which employees identify with their employer, and individual job performance. Without attachment and performance, organizational effectiveness becomes all but impossible.

\section{Managerial policies and practices}

Policies at the macro (entire company) level determine the overall goal structure of the firm. Policies at the micro (departmental) level influence the individual goals of the various corporate functions, such as warehousing, traffic, order processing and customer service. Macro and micro policies in turn affect the procedures and practices of the organization. The planning, coordinating and facilitating of goal-directed activities - which determine organizational effectiveness - depend on the policies and practices adopted by the firm at the macro and micro levels. A number of factors can aid the logistics executive in improving the effectiveness of the organization. Six of the most important factors that have been identified are: strategic goal setting; resource acquisition and utilization; performance environment; communication process; leadership and decision-making and organizational adaptation and innovation.

Strategic goal setting involves the establishment of two clearly defined sets of goals: the overall organization goal or goals, and individual employee goals. Both sets must be compatible and aimed at maximizing company-employee effectiveness.

Resource acquisition and utilization includes the use of human and financial resources, as well as technology, to maximize the achievement of corporate goals and objectives.

The performance environment is concerned with having the proper organizational climate to motivate employees to maximize their effectiveness and, subsequently, the effectiveness of the overall logistics function. Strategies that can be utilized to develop a goal-directed performance environment include proper employee selection and placement, training and development programmes, task design and performance 
evaluation, combined with a reward structure that promotes goal-orientated behaviour.

One of the most important factors influencing logistic effectiveness in any organization is the communication process. Without good communications, logistics policies and procedures cannot be effectively transmitted throughout the firm, and the feedback of information concerning the success or failure of those policies and procedures cannot take place. Communication flows within the logistics area can be downward, upward or horizontal.

Comparable to the importance of effective communication in an organization is the quality of leadership and decision-making expertise exercised by the senior logistics executive. If the top executive is a highly capable and respected individual who makes thoughtful, logical and consistent decisions, then the logistics organization that reports to him or her is also likely be highly effective. Conversely, a logistics organization led by an executive who lacks the necessary leadership and decision-making skills will not usually be as efficient.

Organizational adaptation and innovation. The environment that surrounds the logistics activity requires constant monitoring. As conditions change, logistics must adapt and innovate to continue to provide an optimal cost-service mix to the firm and its markets. Examples of fluctuating environmental conditions include changes in transportation regulations, service requirements of customers, degree of competition in the firm's target markets, economic or financial shifts in the marketplace and technological advances in the distribution sector. It is important that adaptation and innovation not be haphazard and unplanned. An effective organization must exhibit stability and continuity; it must find a unique offering it can deliver to the market and stick with it to provide customer value.

\section{An approach to developing an optimal logistics organization}

Logistics organizations evolve and change. As an executive attempts to structure a new logistics organizational unit or perhaps restructure an existing one, he or she should proceed through the following steps or stages: research corporate strategy and objectives; organize functions in a manner compatible with the corporate structure; define the functions for which the logistics executive is accountable; know his or her management style; organize for flexibility; know the available support systems and understand and plan for human resource allocation so that it complements the objectives of both the individual and organization.

\section{Corporate objectives}

Overall corporate strategy and objectives provide the logistics activity with long-term direction. They provide the underlying foundation and guiding light for each functional component of the firm - finance, marketing, production and logistics. The logistics must support the overall corporate strategy and objectives. It is imperative that logistics executives completely understand the role their activity will play in carrying out corporate strategy. Furthermore, the logistics organizational structure must be compatible with the primary objectives of the firm.

\section{Corporate structure}

While the specific organizational structure of the logistics activity is affected by the overall corporate structure, logistics is increasingly being centralized. In reporting relationships, logistics will typically report to the marketing group if the firm is a consumer goods company and to manufacturing/operations/administration if the firm is primarily an industrial goods producer. Logistics is often a separate organizational 
activity reporting directly to the CEO in firms that have a combination of consumer and industrial goods customers. This practice is growing as the strategic importance of logistics is more widely recognized.

\section{Functional responsibilities}

Identifying a clear definition of the function of the logistics organization can be difficult, especially if the function has been restructured from an organizational structure having a traditional responsibility. It is important to most of the logistics subfunctions housed under a single division or department. Full functional responsibility in one department allows the firm to implement the concepts of integrated logistics management and total cost trade-offs.

\section{Management style}

Almost as important as the formal structure of the organization is the management style of the senior logistics executive. Many firms have undergone significant changes in personnel, employee morale and productivity as a result of a change in top management. Organizational restructuring does not necessarily have to occur. The style or personality of the senior logistics executive, and to a lesser degree his or her lower-level managers, influences the attitudes, motivation, work ethic and productivity of employees at all levels of the organization. Management style is a vital ingredient to the success of a firm's logistics mission and is one of the primary reasons that many different organizational structures can be equally effective.

\section{Flexibility and support systems}

Any logistics organization must be able to adapt to the changes that will inevitably occur. Unresponsive and unadaptable organizations typically lose their effectiveness after a period of time. While it may be difficult to anticipate future changes in the marketplace or the firm, the logistics organization must be receptive to those changes and respond to them in ways that are beneficial to the firm. The nature of the logistics activity makes support systems essential. The logistics organization cannot exist on its own. There must be a variety of support services as well as support specialists available to aid the logistics department or division.

\section{Human resource considerations}

Perhaps the most important component of an effective logistics organization is people. It is the people who ultimately determine how well the company operates. Therefore, employees' skills and abilities, pay scales, training programmes, selection and retention procedures, and other employee-related policies, are vital to the structuring or restructuring of a logistics organization. Logistics managers are essential to a successful organization. Productive and efficient employees must be effectively led. Managers must possess certain important qualities or characteristics: personal integrity and an awareness of business ethics, the ability to motivate, planning skills, self-motivation, managerial control, effective oral communication, supervisory ability, problem-solving ability and self-confidence (Murphy and Poist, 1991). Successful organizations are those that blend the optimal combination of organizational structure, planning process, people and style.

\section{Conclusions}

As companies have extended their supply chains internationally, they have been forced to confront the issue of how to structure their global logistics organization. In their different ways, these companies have moved towards the same conclusion: 
effectiveness in global logistics can only be achieved through a greater element of centralization. This in many respects runs counter to much of the conventional wisdom, which tends to argue that decision-making responsibility should be devolved and decentralized at least to the strategic business unit level. This philosophy has manifested itself in many companies in the form of strong local management, often with autonomous decision making at the country level. The strategic structuring and overall control of logistics flows must be centralized to achieve worldwide optimization of costs.

\section{References}

Christopher, M. (2005), Logistics and Supply Chain Management - Creating Value Adding Networks, FT Prentice-Hall, London.

Droge, C., Germain, R. (1998), The design of logistics organizations, The Logistics and Transportation Review, Vol. 34, No. 1, 25-37.

Fuller, J.B., O’Connor, J., Rawlinson, R. (1993), Tailored logistics: the next advantage, Harvard Business Review, Vol. 72, No. 3, 87-98.

Grant, D.B., Lambert, D.M., Stock, J.R., Ellram, L.M. (2006), Fundamentals of Logistics Management, New York, McGraw-Hill Education.

Kanter, R.M., Stein, B.A., Jick, T.D. (1992), The challenge of organizational change - how companies experience it and leaders guide it, New York, Free Press.

Kueng P., Krahn A.J.W. (2004), Building a Process Performance Measurement System: some early experiences, Journal of Scientific\&Industrial Research, 2004.

Murphy, P.R., Poist, R.F. (1991), Skill requirements of senior-level logistics executives: an empirical assessment, Journal of Business Logistics, Vol. 12, No. 2, 83-7.

Roberts, J. (1990), Formulating and implementing a global logistics strategy, International Journal of Logistics Management, Vol. 1, No.2.

Steers, R.M. (1977), Organizational effectiveness: a behavioral view, Santa Monica, CA: Goodyear. 